\title{
Unbound Water Content From Application of Adsorption Theory
}

\author{
William V. Loebenstein
}

Institute for Materials Research, National Bureau of Standards, Washington, D.C. 20234

(May 19, 1975)

\begin{abstract}
It is standard procedure to fit an applicable isotherm equation to water vapor adsorption data using the method of least squares in arriving at a value for the surface area accessible to the water molecule. The least squares technique has been extended in the present investigation to determine, in addition and simultaneously, a "best value" for the zero-humidity sample weight of the material. The application is equally valid for desorption insofar as the zero-humidity weight is concerned, although the derived value for "surface area" from desorption data will be over-estimated in the general case because of hysteresis. There is no limitation on the range of humidities since the method is not restricted to the BET equation (i.e., between 0.1 and 0.3 r.h.). In fact, good agreement with the zerohumidity points measured experimentally has been obtained even from drying curves in which the relative humidity has been confined to the region above 50 percent. An iterative method is employed in the calculations for which computer assistance is especially adaptable. Fortran IV programs are included in the appendix whose use requires no extensive computer experience. A fraction of a second in computer processing time is all that is required for each determination.
\end{abstract}

Key words: Adsorption; computer application; desorption; dry weight determination; moisture content; surface area; water content; water vapor adsorption.

\section{Introduction}

What constitutes the dry weight of a solid has never been completely resolved. Some materials like hydroxide gels of aluminum, silicon, iron, etc., continue to lose water when evacuated at ambient temperatures and more so on heating, yet a trace of water always seems to remain. Other materials readily give up their water, but suffer irreversible changes in the process. This leads to the adoption of a concept of water of constitution as distinguished from excess water.

A novel approach to this problem of dry weight prediction is portrayed in this paper based on the assumption that adsorbed water is certainly not water of constitution, and, consequently, is excess. To establish the precise point of dryness, therefore, it is only necessary to determine the weight of the solid under conditions where the amount of physically adsorbed water would be zero. This is determined by fitting vapor adsorption theory to the experimental data by an unorthodox application of the least-squares technique.

Since the development in 1938 of the Brunauer, Emmett, and Teller (BET) multimolecular adsorption free-surface equation $[1]^{1}$, many other adsorption isotherm theories $[2,3,4,56,7]$ have appeared in the literature. Most of the resultant isotherm equations,

${ }^{1}$ Figures in brackets indicate the literature references at the end of this paper. despite their differences, shared certain important attributes:

(1) They were expressable in some linear form.

(2) Each equation possessed physically significant parameters which could be evaluated either from the slope or intercept of the experimental plot or a combination of both.

(3) These parameters bore a simple functional relationship with the specific surface of the adsorbent.

For these reasons, any such theory would appear to qualify as a candidate for prediction of dry weight in the method to be described.

At the onset of this study, no a priori preference was made of any one adsorption theory over the others, although, in practice, the BET equation is probably more widely used than all of the others combined. This reason alone would justify its inclusion among the theories selected. In addition to the BET, the other adsorption theories tested in this work were: the Polarization theory [6], Harkins and Jura (H-J) theory [3], and Polanyi's Potential theory [6].

It will be shown that the same experimental points that are normally employed using least-square methods to determine only the surface area of an adsorbent can, at the same time, be called upon to furnish an additional piece of information; namely, its dry weight. 


\section{Theoretical Development}

(1) The BET [1] free-surface equation in its most familiar form may be represented as a linear function of the relative pressure:

$$
y=a+b x
$$

where $x=$ relative pressure (humidity, where water vapor is the adsorbate) expressed as a dimensionless decimal such that $0 \leqslant x \leqslant 1$. The dependent variable $y$ is, in itself, an expression:

$$
y=x /[q(1-x)]
$$

containing both $x$ and $q$. The latter quantity represents the number of moles of adsorbate per $\mathrm{g}$ of adsorbent obtained under steady state conditions at the corresponding value of $x$.

The $y$-intercept, $a$, and slope, $b$, are the parameters $1 /\left(q_{m} c\right)$ and $(c-1) /\left(q_{m} c\right)$, respectively. The quantity $q_{m}$, in turn, represents the number of moles of adsorbate required to constitute a monolayer and, as such, is proportional to the surface area. The $c$-value is related exponentially to an average energy of adsorption. In the conventional application of eq (1), the parameters $a$ and $b$ are evaluated from the experimentally obtained adsorption points $(x, q)$ preferably by use of the method of least squares [8]. These "best" estimates of $a$ and $b$ are then used to obtain $q_{m}$ and $c$. Finally, the surface area is obtained conventionally by multiplying $q_{m}$ by an appropriate constant sometimes referred to as the "packing factor."

Most laboratory workers in surface chemistry are painfully aware of the fact that the good linearity of eq (l) is destroyed when the experimentally determined initial weight of the sample is in error. One should, therefore, expect that the best straight line would result only when a zero-point weight very close to the correct value is used in the calculations. This criterion was employed in the present investigation for determining the dry weight of a solid adsorbent when water vapor was the adsorbate. In other words, the humidified sample weights themselves, utilizing a least-squares technique, were permitted to determine that value of the dry weight, $p$, along with the usual two parameters $a$ and $b$ required to optimize the linearity:

If $W_{i}$ represents the weight (in grams) of the sample at the $i$ th point corresponding to a relative humidity $x_{i}$, the number of moles of water vapor adsorbed per $\mathrm{g}$ of dry adsorbent would be

$$
q_{i}=\frac{W_{i}-p}{18 p} .
$$

The value of $x_{i}$ is assumed to be error-free here as it is in the conventional derivation.

The residual, $R_{i}$, is the experimental error of the ordinate of the $i$ th point as indicated by the difference $y_{i}-\left(a+b x_{i}\right)$. Equations (1), (2), and (3) may be combined to yield:

$$
R_{i}=\frac{18 x_{i} p}{\left(1-x_{i}\right)\left(W_{i}-p\right)}-\left(a+b x_{i}\right) .
$$

It is required to determine the values of the three parameters $p, a$, and $b$ for which the sum of the squares of the residuals is a minimum. ${ }^{2}$

This amounts to solving three nonlinear simultaneous equations for these parameters given by eqs (5), (6), and (7):

$$
\begin{gathered}
\frac{\partial}{\partial p}\left[\sum_{i=1}^{n} R_{i}^{2}\right]=0 \\
\frac{\partial}{\partial a}\left[\sum_{i=1}^{n} R_{i}^{2}\right]=0 \\
\frac{\partial}{\partial b}\left[\sum_{i=1}^{n} R_{i}^{2}\right]=0 .
\end{gathered}
$$

By taking the partial derivative of the summation with respect to $p$ as indicated by eq (5), the result is eq (8):

$$
\begin{array}{r}
a \sum_{i=1}^{n} \frac{x_{i} W_{i}}{\left(1-x_{i}\right)\left(W_{i}-p\right)^{2}}+b \sum_{i=1}^{n} \frac{x_{i}^{2} W_{i}}{\left(1-x_{i}\right)\left(W_{i}-p\right)^{2}} \\
-18 p \sum_{i=1}^{n} \frac{x_{i}^{2} W_{i}}{\left(1-x_{i}\right)^{2}\left(W_{i}-p\right)^{3}}=0 .
\end{array}
$$

In the same way, eqs (6) and (7) give rise to eqs (9) and (10), respectively.

$$
\begin{array}{r}
a n+b \sum_{i=1}^{n} x_{i}=18 p \sum_{i=1}^{n} \frac{x_{i}}{\left(1-x_{i}\right)\left(W_{i}-p\right)} \\
a \sum_{i=1}^{n} x_{i}+b \sum_{i=1}^{n} x_{i}^{2}=18 p \sum_{i=1}^{n} \frac{x_{i}^{2}}{\left(1-x_{i}\right)\left(W_{i}-p\right)}
\end{array}
$$

A cursory inspection of eqs (8), (9), and (10) discloses that the nonlinearity is ascribable entirely to the unknown parameter, $p$. In fact, the terms to the left of the equals signs in eqs (9) and (10), respectively, are identified with those obtained [8] in the "normalized" equations during the derivation of the leastsquare solution for a linear system. This observation suggests a relatively simple method for the simultaneous solution of eqs (8), and (9), and (10) for the parameters $p, a$, and $b$. An initial value $p_{1}$ is selected for $p$ which is not quite as large as the lowest value of $W_{i}$. This value of $p$ is substituted in eqs (9) and (10)

${ }^{2}$ This is rigorously valid only when the error represented by $R_{i}$ has a normal (Gaussian) distribution over its entire range. Experience has confirmed that in the present application,
this assumption is reasonably well approximated. 
making it possible to solve them simultaneously for $a$ and $b$ which are then designated $a_{1}$ and $b_{1}$, respectively. The values of $a_{1}, b_{1}$, and $p_{1}$ are then substituted in the left side of eq (8). The resultant value is called $\Phi_{1}$.

Since $p_{1}$ was initially selected to be somewhat high, it is decreased by a small predetermined amount to obtain its second iterative value, $p_{2}$. Corresponding values of $a_{2}$ and $b_{2}$ are again calculated from eqs (9) and (10), as before, and all three contribute to the determination of $\Phi_{2}$ from eq (8). If $\Phi_{2}$ has the same sign as $\Phi_{1}$, it should be smaller in absolute value and the iterative process is repeated until there is a change in sign of $\Phi$. At that point the incremental change in $p$ is reduced to one-tenth of its previous value and its sign is automatically reversed. Again, the new direction is maintained with the smaller increment until the next change in sign of $\Phi$ is encountered. The process is repeated until negligible changes are obtained in successive values of $p, a$, and $b$ while successive values of $\Phi$ approach zero in the limit. Usually this occurs within about 25 iterations and gives an estimate of surface area and goodness of fit as well as the dry weight of the sample.

The entire process has been programmed for computer operation (FORTRAN IV) and is given in the appendix (fig. Al) in a form used with a teletype timesharing terminal. ${ }^{3}$

The values for the slope and the intercept were combined in the usual way at the end of each iteration by taking the reciprocal of their sum to obtain $q_{m}$. The factor $7.529 \times 10^{4} \mathrm{~m}^{2} / \mathrm{mol}$ was used [10] to convert $\boldsymbol{q}_{m}$ to surface area. Only the final value, however, after convergence was complete could be considered valid.

(2) The Harkins and Jura (H-J) isotherm equation.

A linear relationship based on a two-dimensional equation of state was proposed by Harkins and Jura [3]. It took the form

$$
\omega=\frac{A}{q^{2}}-B
$$

where

$$
\omega=\ln (1 / x)
$$

while $A$ and $B$ are constants.

There are no relative humidity restrictions on its range of applicability. (This is in contrast to the more familiar BET equation valid only within the inclusive values from about 0.1 to 0.3 .) The surface area applicable to the H-J equation is proportional to the square root of the parameter $A$. The proportionality constant is, of course, dependent upon the adsorbate and the

\footnotetext{
${ }^{3}$ The Control Data "KRONOS" System (6000 series) high-speed digital computer required only about $1^{1 / 4} \mathrm{~s}$ in a typical computation. The central computer time can be further shortened to about $1 / 3 \mathrm{~s}$ when several independent determinations are performed, since shortened to about $1 / 3 \mathrm{~s}$ when several independent determinations are performed, since
the compiling time (c.a. $1 \mathrm{~s}$ ) need not be repeated. Similar results were obtained using the Sperry Rand "UNIVAC 1108" System.

Certain commercial materials and equipment are identified in this paper in order to specify adequately the experimental procedure. In no case does such identification imply recommendation or endorsement by the National Bureau of Standards, nor does it imply that the material or equipment identified is necessarily the best available for this purpose.
}

temperature of the isotherm. The value used in this work corresponding to water vapor at $23{ }^{\circ} \mathrm{C}$ was $5.620 \times 10^{4} \mathrm{~m}^{2} / \mathrm{mol}[12]$.

Using the same procedure described for the BET theory, the least square normalized equations resulting from the $\mathrm{H}-\mathrm{J}$ isotherm equation are:

$$
\begin{array}{r}
\Phi=A p\left\{\sum_{i=1}^{n} \frac{W_{i} \omega_{i}}{\left(W_{i}-p\right)^{3}}-(18)^{2} A p^{2} \sum_{i=1}^{n} \frac{W_{i}}{\left(W_{i}-p\right)^{5}}\right. \\
\left.+B \sum_{i=1}^{n} \frac{W_{i}}{\left(W_{i}-p\right)^{3}}\right\} \\
(18)^{2} p^{2} A \sum_{i=1}^{n} \frac{1}{\left(W_{i}-p\right)^{2}}-B n=\sum_{i=1}^{n} \omega_{i} \\
(18)^{2} p^{2} A \sum_{i=1}^{n} \frac{1}{\left(W_{i}-p\right)^{4}}-B \sum_{i=1}^{n} \frac{1}{\left(W_{i}-p\right)^{2}} \\
=\sum_{i=1}^{n} \frac{\omega_{i}}{\left(W_{i}-p\right)^{2}} .
\end{array}
$$

The iterative procedure previously described was again resorted to and a computer program given in appendix (fig. A2) was tailored to accommodate the H-J equation. This resulted in converged estimates of dry weight and surface area while at the same time affording a measure of goodness of fit.

(3) Other Isotherm Equations

The Polarization Equation of deBoer and Zwikker [9]:

$$
q=a^{\prime}+b^{\prime} \ln \omega
$$

and the Polanyi Potential Theory [9]:

$$
q=a^{\prime \prime}+b^{\prime \prime} \omega^{-1 / 3}
$$

were both subjected to the same treatment as described for the other two theories and will be discussed in a later section.

\section{Equipment and Procedures}

The gravimetric adsorption equipment employed used a circulatory flow system and a means for supplying water vapor at predetermined humidities to the carrier gas as described in a recent publication [10]. A drying tube mounted vertically and filled with $\mathrm{P}_{2} \mathrm{O}_{5}$ supported on glass wool had a trap sealed to its lower end for holding back the phosphoric acid produced and isolating it from the gas stream during desiccation of a sample. The drying step was carried out at room temperature $\left(23^{\circ} \mathrm{C}\right)$ as were all of the humidity exposures. Drying was performed either initially or at the end of a humidity sequence, depending upon whether it was an adsorption or desorption series. The zero-humidity data were, of course, not used in the calculations and served only as experi- 
mental verification of the calculated values. Saturated salt solutions were used for obtaining the desired humidities, details of which were described previously [10]. However, any standard commercial equipment would work equally well in order to apply the technique in any particular case.

The order in which the experimental points are obtained is extremely important. They must be in a continually decreasing (desorption or drying) or in a continually increasing (adsorption) sequence to avoid hysteresis scanning loops [11].

Table 5 shows that even low area adsorbents respond well in dry weight prediction regardless of whether adsorption or desorption data are used.

The dry weights predicted in table 6 are significant because most of the data were collected at relative humidities above 50 percent. The ability to do this is especially valuable in nondestructive testing where complete dehydration might cause irreversible changes in the sample.

\section{Results}

Tables 1 through 6 summarize the results of several determinations. The grouping of the experiments helps to emphasize the capabilities as well as the limitations inherent in the method.

Most of the examples in table 1 give reasonably good agreement in surface area between BET and H-J. The experimentally measured dry weights, in the majority of cases, are slightly greater than the calculated values. This suggests the possibility that the last traces of physically adsorbed water may not have been completely removed by the experimental procedure used. In one instance this effect is rather striking. ${ }^{4}$

The two experiments involving barium glass ${ }^{5}$ (water extracted) represent the initial and final adsorption sequence in an adsorption-desorption-adsorption cycle in which the relative humidity started at zerowent stepwise to saturation - then down to zero-and finally back up again to 0.334 .

Good agreement between surface area predicted from desorption data with that from adsorption is not generally to be expected. Table 2 shows exceptions occur where hysteresis is either absent entirely or negligibly small.

Some insight may be deduced from the results of both isotherm equations even when only desorption (drying) data are available. Fair agreement between the "areas" as shown in the latter two examples of table 3 where hysteresis is known to be virtually nonexistent suggests that these values may be reasonably valid estimates of the true surface area.

Table 4 is self explanatory and shows consistency of both surface areas and predicted dry weights between widely different portions of the adsorption isotherm.

${ }^{4}$ See Cellulose Acetate Membrane (table 4).

${ }^{5}$ Corning Glass Company X95-1FD.

TABLE 1. Adsorption

Low humidity range $(0.082 \rightarrow 0.334)$

Comparison of BET with H.J for the Same Data

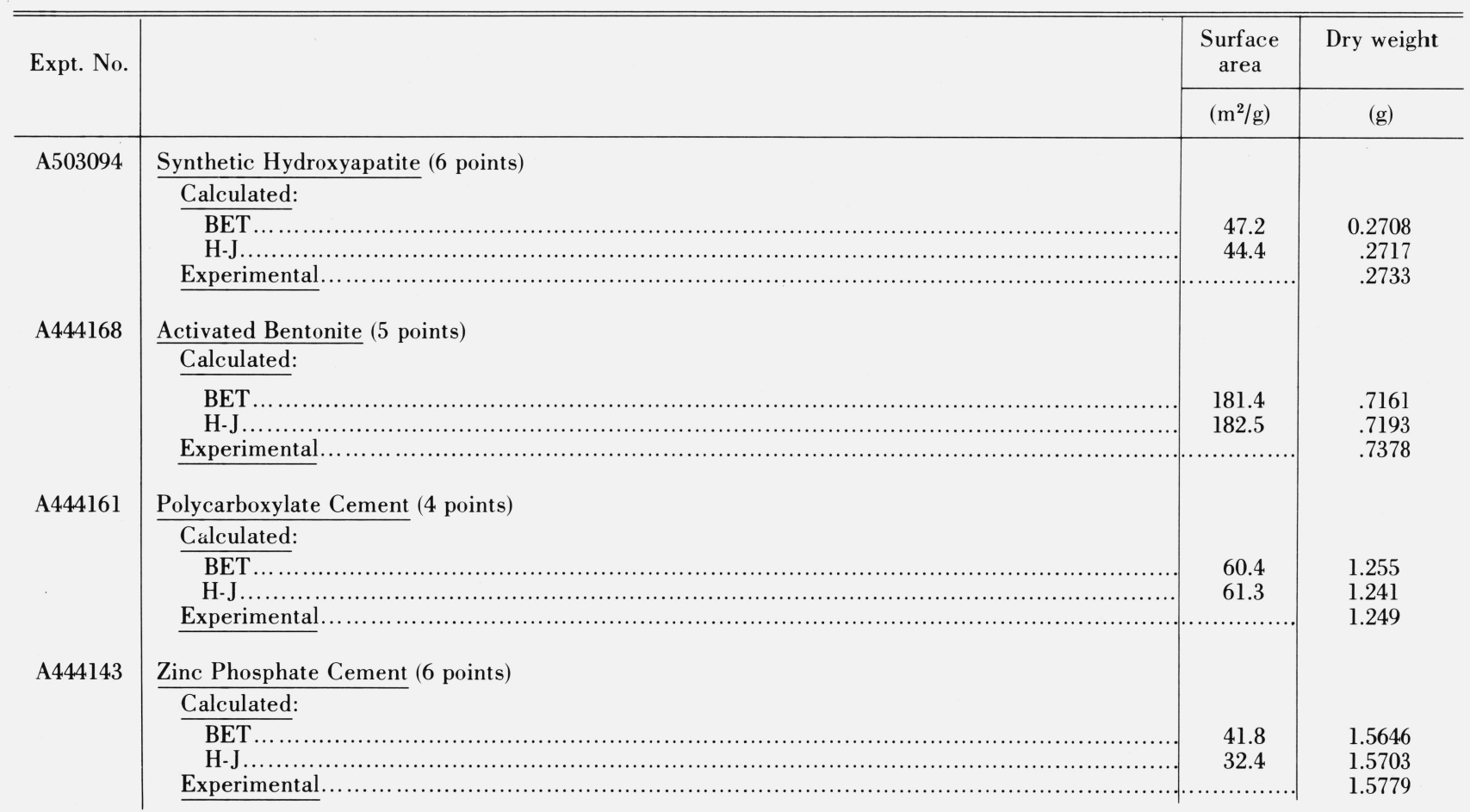


TABle 1. Adsorption-Continued

\begin{tabular}{|c|c|c|c|}
\hline \multirow[t]{2}{*}{ Expt. No. } & & $\begin{array}{l}\text { Surface } \\
\text { area }\end{array}$ & Dry weight \\
\hline & & $\left(\mathrm{m}^{2} / \mathrm{g}\right)$ & (g) \\
\hline \multirow[t]{4}{*}{ A444155 } & $\frac{\text { Barium Glass }- \text { as received }}{\text { Calculated: }}$ (6 points) & & \multirow{6}{*}{$\begin{array}{l}1.2886 \\
1.2889 \\
1.2895\end{array}$} \\
\hline & BET $\ldots \ldots \ldots \ldots \ldots \ldots \ldots \ldots \ldots \ldots \ldots \ldots \ldots \ldots \ldots \ldots \ldots$ & 3.22 & \\
\hline & & 3.15 & \\
\hline & Experimental...................... & & \\
\hline \multirow[t]{5}{*}{ A444156 } & Barium Glass - Water Extracted ( 4 points) & & \\
\hline & Calculated: & & \\
\hline & 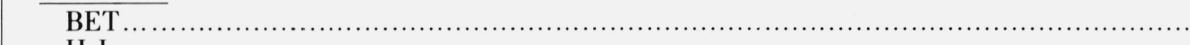 & 8.7 & \multirow{3}{*}{$\begin{array}{r}0.9636 \\
.9648 \\
.9649\end{array}$} \\
\hline & H.J.................................. & 4.6 & \\
\hline & 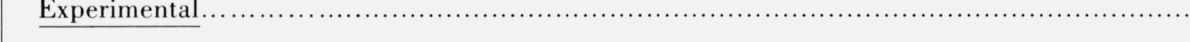 & & \\
\hline \multirow[t]{4}{*}{ A444175 } & Barium Glass - Water Extracted (6 points) & & \multirow{7}{*}{$\begin{array}{l}- \\
.9646 \\
.9657\end{array}$} \\
\hline & $\frac{\text { Calculated: }}{\text { BET (no convergence) } \ldots \ldots \ldots \ldots \ldots \ldots \ldots \ldots \ldots \ldots \ldots \ldots \ldots \ldots \ldots}$ & & \\
\hline & 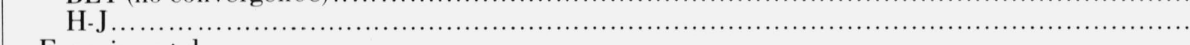 & 9.5 & \\
\hline & 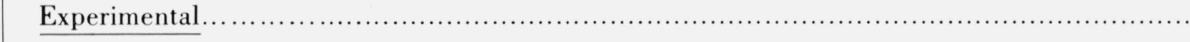 & & \\
\hline \multirow[t]{5}{*}{ A444164 } & Zinc Oxide-Eugenol Cement (4 points) & & \\
\hline & Calculated: & & \\
\hline & 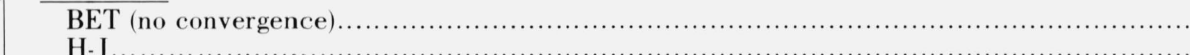 & & \\
\hline & $\begin{array}{c}\mathrm{H} \\
\mathrm{e} \\
\text { Experimental }\end{array}$ & 5.2 & \multirow{2}{*}{$\begin{array}{l}3.1274 \\
3.1297\end{array}$} \\
\hline & & & \\
\hline
\end{tabular}

TABLE 2. Adsorption versus desorption

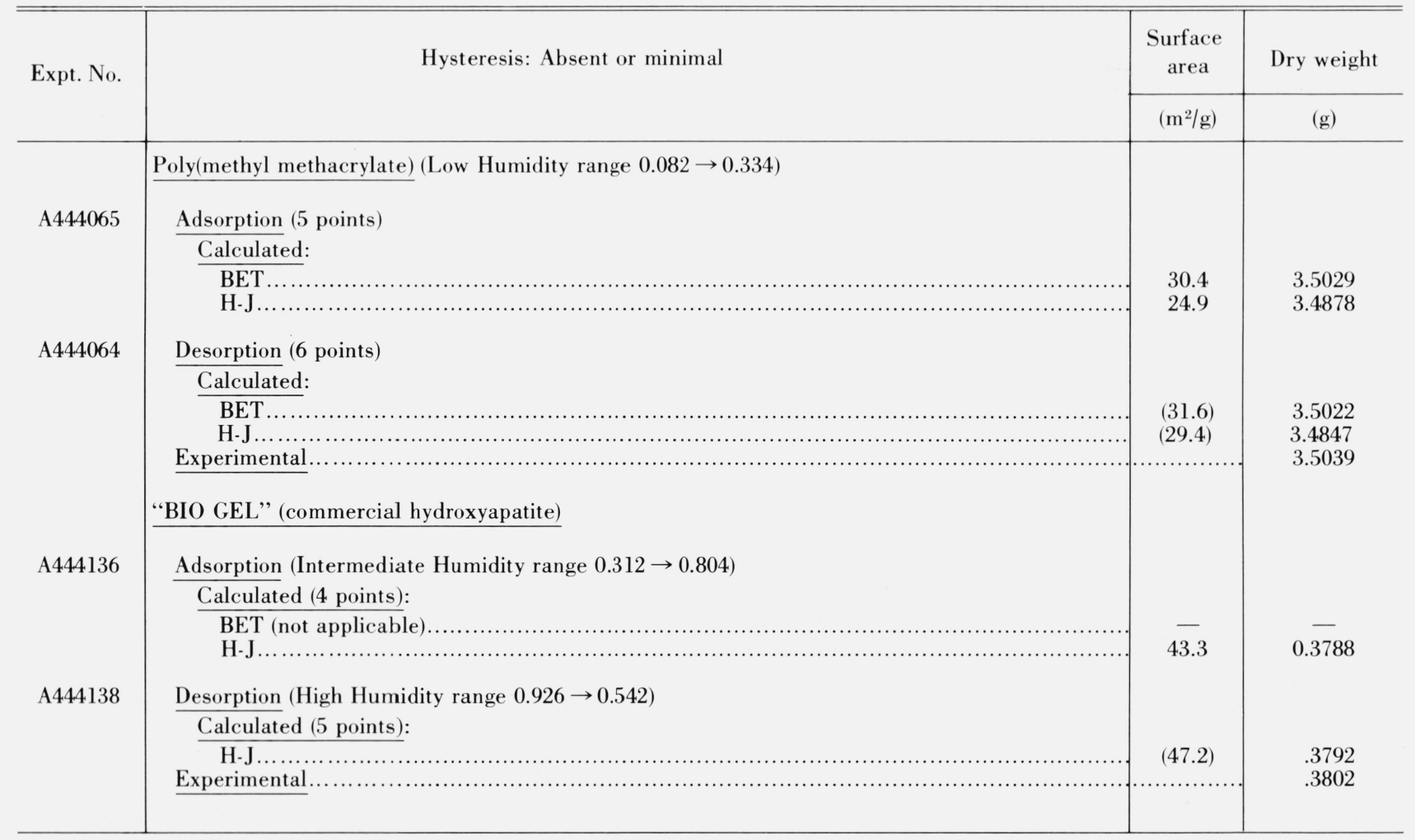


TABLE 3. Desorption

Low Humidity Range $(0.334 \rightarrow 0.082)$ Comparison of $\mathrm{BE} \Gamma$ with $\mathrm{H} \cdot \mathrm{J}$ for the same data

\begin{tabular}{|c|c|c|c|}
\hline Expt. No. & & $\begin{array}{c}\text { Surface } \\
\text { area }\end{array}$ & Dry weight \\
\hline & & $\left(\mathrm{m}^{2} / \mathrm{g}\right)$ & (g) \\
\hline A444159 & 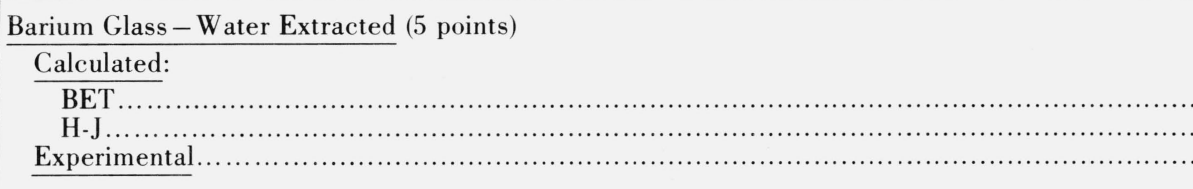 & $\begin{array}{r}(9.2) \\
(2.3)\end{array}$ & $\begin{array}{r}0.9639 \\
.9659 \\
.9657\end{array}$ \\
\hline A503137 & 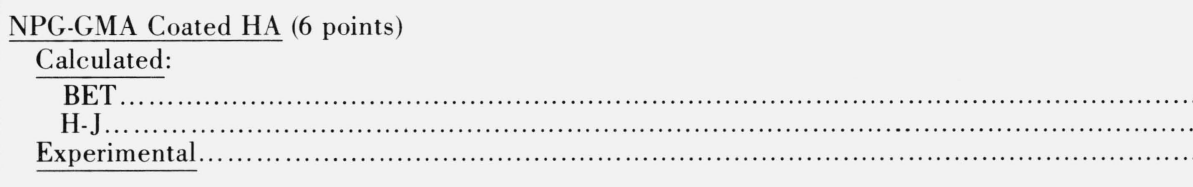 & $\begin{array}{l}(14.6) \\
(12.6)\end{array}$ & $\begin{array}{l}.4808 \\
.4799 \\
.4805\end{array}$ \\
\hline A444139 & 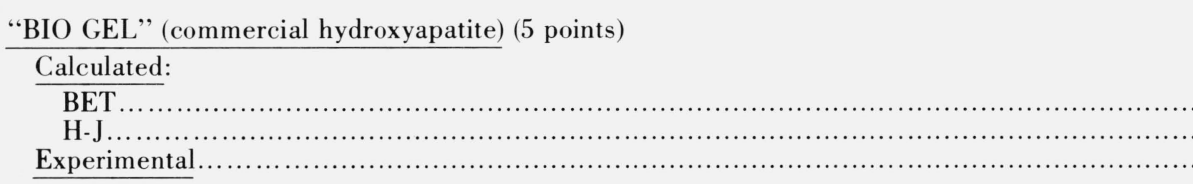 & $\begin{array}{l}(40.5) \\
(59.4)\end{array}$ & $\begin{array}{l}.3792 \\
.3784 \\
.3811\end{array}$ \\
\hline
\end{tabular}

TABLE 4. Adsorption

Low humidity versus high humidity

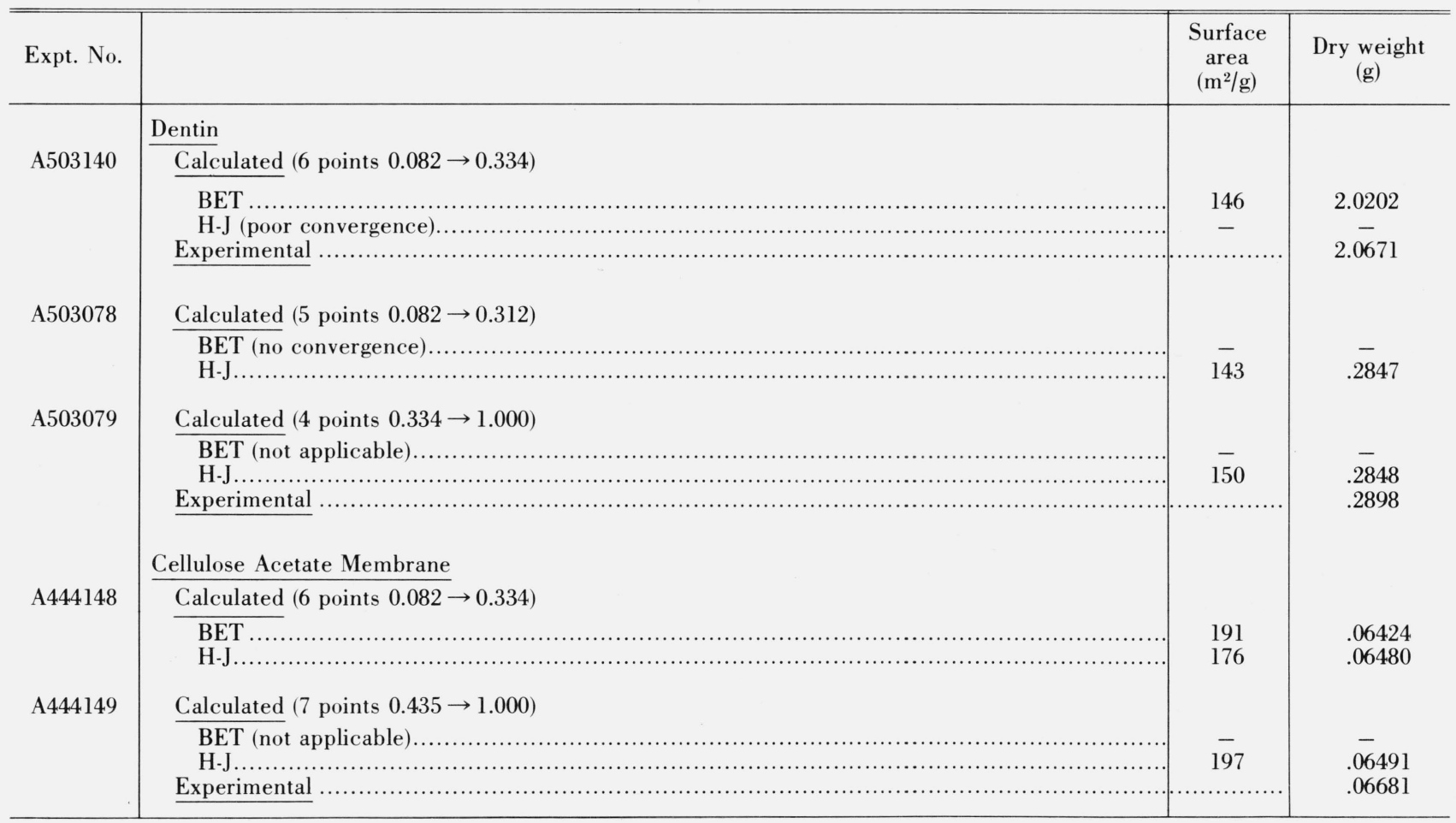




\begin{tabular}{|c|c|c|c|}
\hline Expt. No. & & $\begin{array}{c}\text { Surface } \\
\text { area } \\
\left(\mathrm{m}^{2} / \mathrm{g}\right)\end{array}$ & $\begin{array}{l}\text { Dry weight } \\
\text { (g) }\end{array}$ \\
\hline \multirow{4}{*}{ A 444124} & Pulverized Dental Amalgam & \multirow{6}{*}{0.44} & \multirow{6}{*}{5.6135} \\
\hline & Adsorption (7 points) & & \\
\hline & Calculated & & \\
\hline & H-J........ & & \\
\hline \multirow[t]{4}{*}{ A444126 } & Desorption (4 points) & & \\
\hline & Calculated & & \\
\hline & H-J......... & \multirow[t]{2}{*}{$(0.74)$} & \multirow{2}{*}{$\begin{array}{l}5.6132 \\
5.6145\end{array}$} \\
\hline & Experimental . & & \\
\hline
\end{tabular}

TABLE 6. High humidity drying (desorption) curves for predicting water content *

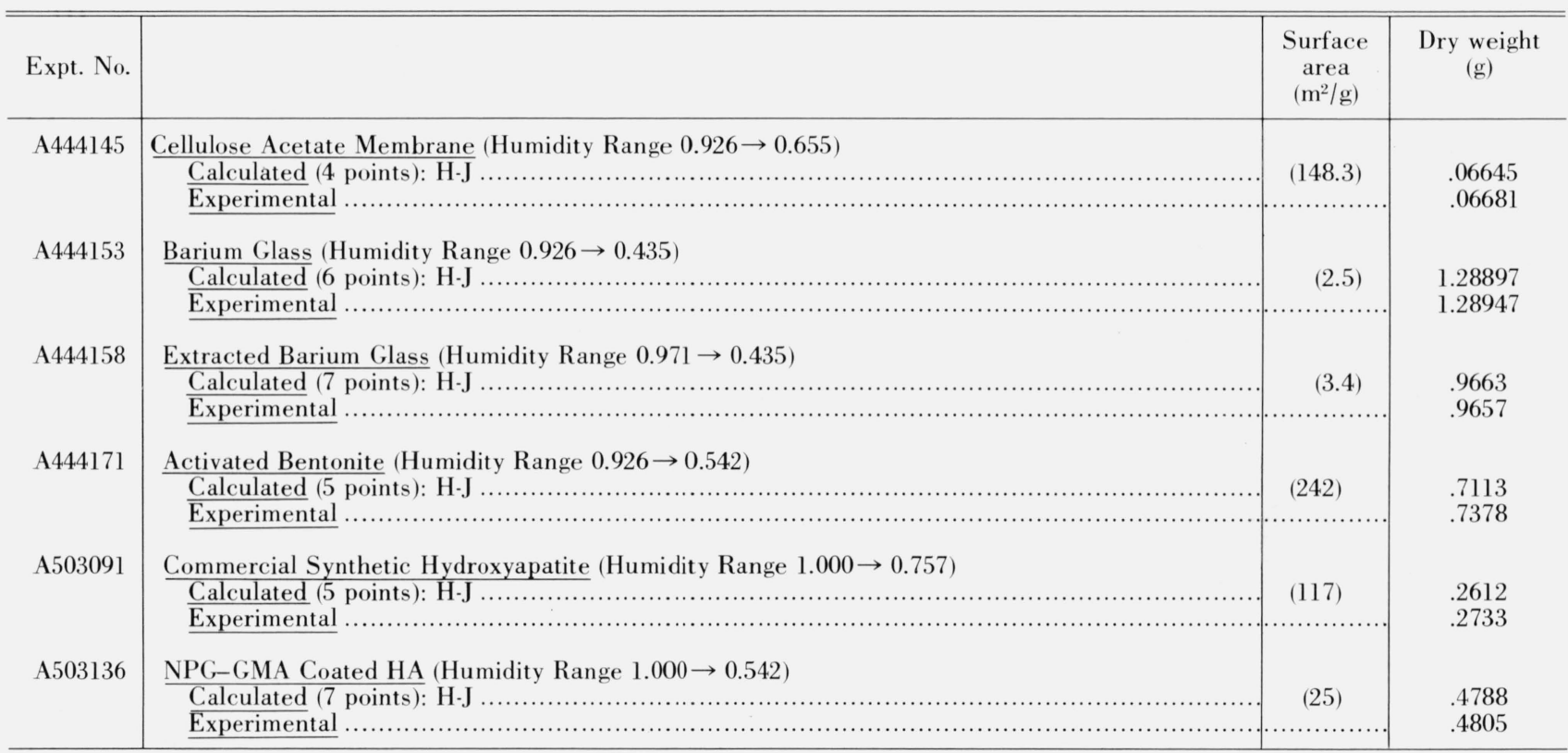

*Other examples included in tables 2 and 5.

\section{Discussion}

The fact that the least-squares technique can be applied successfully for determining unbound water content along with surface area for the BET and the $\mathrm{H}-\mathrm{J}$ isotherm equations raises the question of whether it would work equally well for other adsorption theories. Accordingly, computer programs were developed for testing the Potential theory and the Polarization theory, each of which could be expressed in linear form [9]. It soon became clear that this method would not be applicable to either one of these latter isotherm equations. They seemed to be "ill-conditioned" or not sufficiently sensitive to perturbation in sample weight to be of practical use in instances where both BET and H-J converge readily. Further testing was therefore abandoned. The possibility remains that still other isotherm equations $[2,4,5]$ (besides the four tested here) might well be adaptable to this technique.

It is instructive to assess the relative advantages of BET and of H-J as applied to the present work:

(1) The H-J would, of course, be used for all values beyond the relative pressure (about 0.3 ) of the applicable BET range.

(2) For very small surface area samples where the points in the BET range may be too erratic for successful convergence, the points higher up on the isotherm may have sufficiently reduced relative error to give successful convergence using H-J.

(3) In the valid BET region where both isotherm equations could be used, the BET equation appeared to be the more sensitive. When the experimental 
error of the points was excessive, neither computer program would converge. At moderate error such that only one equation led to successful convergence it was usually H-J (see tables 1 and 4 ).

(4) In many instances where no convergence was found when using the BET equation, a minimum in the residual variance (mean-square deviation of the ordinates of the experimental points from the assumed curve) was useful as a rough estimate of the correct dry weight and surface area.

(5) When convergence was attained using both isotherm equations and the predicted surface areas were in reasonably good agreement (see first four experiments in table 1), it served to reinforce one's confidence in the validity of the results. When agreement was somewhat less than desired for a homogeneous adsorbent (see table 1, Expt A444156), the BET value would be preferred. Note that the BET surface area value of $8.7 \mathrm{~m}^{2} / \mathrm{g}$ (rather than the H-J value of 4.6) was in better agreement with the results of Experiment A444175 for the same adsorbent (also table 1) for which the H-J value of $9.5 \mathrm{~m}^{2} / \mathrm{g}$ was calculated.

(6) For a nonhomogeneous adsorbent where aggregate behavior might lead to an erroneous BET value [12] as a result of large differences in energies of adsorption among the components of the solid, the H-J area would always be preferable.

Throughout tables 2, 3, 5, and 6 surface area values obtained from desorption experiments are shown in parenthesis. They are likely to be erroneous unless the desorption curve is substantially a retracing of the adsorption curve (absence of hysteresis). This is a property of the adsorbent-adsorbate system and must be considered case by case. Virtual absence of hysteresis is portrayed by the materials listed in table 2 and exists to only a slight degree for those listed in table 3. The dry weight values, however, are just as valid with desorption as with adsorption provided the desorption originates at saturation resulting in a descending boundary curve [13]. Other instances which have been found to agree with the experimental results for dry weight include primary descending scanning curves; although the predicted surface area would not be valid. A case in point is illustrated by an experiment not shown in the tables. Water vapor was adsorbed on a desiccated sample of Bio Gel ${ }^{6}$ to a relative humidity of 0.804 after which seven additional successive desorption values were obtained. Convergence was successful using $H$-J resulting in a predicted dry weight of $0.3788 \mathrm{~g}$ compared with the experimental value of $0.3811 \mathrm{~g}$ obtained after taking the sample again to dryness.

Desorption along scanning curves other than those already mentioned as well as adsorption along scanning curves, will invariably result in erroneous values for dry weight prediction in spite of satisfactory convergence of the computer program. Two experiments performed with the same sample of human dentin will serve to illustrate this. In both cases, the starting

${ }^{6}$ BIO-RAD Laboratories, Richmond, California. point was saturation (relative humidity $=1.00$ ). In the first experiment (A444090), desorption occurred along the descending boundary curve to a value of 0.175 relative humidity. This was followed by adsorption along a primary ascending scanning curve to a relative humidity of 0.757 . Desorption was next carried out stepwise along this secondary descending scanning curve. The sample weights measured were: $0.249303 \mathrm{~g}, 0.247758 \mathrm{~g}, 0.246568 \mathrm{~g}$, and $0.245402 \mathrm{~g}$ at the corresponding relative humidities of $0.757,0.655$, 0.542 , and 0.435 , respectively. The dry weight predicted from using the H-J equation was $0.2356 \mathrm{~g}$ as compared with $0.2288 \mathrm{~g}$ measured experimentally. In the other experiment (A444091) the initial turning point between the descending boundary curve and the primary ascending scanning curve took place at 0.122 r.h. (instead of 0.175 r.h.). In this experiment, the sample weights at the same respective humidities along the secondary descending scanning curve were $0.248456 \mathrm{~g}, 0.247364 \mathrm{~g}, 0.245881 \mathrm{~g}$, and $0.244989 \mathrm{~g}$. These values gave rise to a predicted dry weight of $0.2369 \mathrm{~g}$. It is significant that in both of these experiments the dry weight was predicted about four percent on the high side compared with the actual measurement. A detailed study of the behavior of scanning curves in adsorption-desorption hysteresis is beyond the scope of this paper [13].

It was stated earlier in this discussion (subparagraph 3) that the BET equation was extremely sensitive regarding the effect of experimental error on convergence of the computer program. If a sufficient number of points are available in a system in which the BET equation is known to be valid and yet the computer program does not converge, it is useful to plot the original data especially when it is impractical (or impossible) to repeat the experiment. If one of the points does not fit a smooth curve which passes through the remaining points, those remaining points may very well allow the computer program to converge. Of course, the results should be examined carefully for reasonableness of the predicted quantities before they are accepted. This suggestion is submitted in lieu of a valid test for outliers [14] in a system as complicated as this.

It is appropriate to caution the reader that the method described in this paper is not proposed as a substitute for measuring the zero humidity point in routine surface area determinations. It is also entirely feasible that experimental errors might combine in such a way as to permit convergence and yet yield incorrect results. In other words, the need for careful experimental work is probably even more important when the additional demand is placed on the sorption points to estimate the zero humidity value as well as the surface area.

Some applications in which the methods described in this paper would be especially valuable are:

(1) Where routine measurements have yielded good linear BE'T results yet, now and then, a sample of the same type of material when plotted in accordance with eq (1) produced a curve instead of a straight line. 
In such instances, the entire experiment would normally have to be discarded and all because an error in the experimental determination of the dry weight was reflected in all the other points on the plot.

(2) Dry weight of materials that evolve gases during decomposition at low pressures.

(3) In agricultural products (such as grain) and other materials where the last traces of water may be extremely slow coming off during drying (desorption), provided again that the isotherm equation employed is known to be appropriate for that system.

(4) In biological applications where viability of the organism (or tissue) would be destroyed by complete drying while, perhaps, equilibration at, say, fifty percent relative humidity might be tolerated, nondestructive determinations of dry weight could be made. This would be especially useful in growth rate studies.

(5) In situations where no other method may be available for estimation of dry weight and/or surface area from previously obtained data which may be incomplete.

\section{Summary}

(1) It has been demonstrated that adsorption or desorption data are capable of estimating the unbound water content of solid adsorbents. This was accomplished by the convergence of a computer program which employed a least-squares technique applied to an appropriate isotherm equation.

(2) The Brunauer, Emmett, and Teller free surface equation and the Harkins and Jura equation were readily adaptable to this treatment (the Polarization equation and the Potential theory equation did not respond).

(3) A valid estimate of surface area was also obtained when data from adsorption experiments were used or with such desorption experiments for which no hysteresis existed. Where there was hysteresis, the predicted surface area while incorrect was a useful order-of-magnitude estimation, usually as an upper limit.

(4) Applications of the technique for determining the dry weights were compared with experimentally measured values for solids which cover a wide range in surface area. The agreement was within about one percent and the calculated dry weight was usually on the low side.

(5) The capabilities as well as the limitation in the application of these methods were compared and discussed.

\section{Appendix. Procedure for Using Isotherm Data With Time Sharing Teletype Terminal}

Fortran Computer programs are given in figure Al for the BET equation in figure A2 for the Harkins and
Jura equation. A minimum of four data points is required, although a larger number is preferred. The adsorption (or desorption) data can be pre-punched on paper tape before connecting the terminal with the computer. (The input format has been designed such that the same data tape may be used with either program.) A typical data file, for example, (A444153) transposed from the tape is shown in table Al. The initial line (here designated as 10) contains:

a. The number of data points in the experiment (in this case, 6).

b. The maximum number of iterations.

c. A starting value (tentative) for the dry weight.

d. The initial decrement (or amount by which the preceding numeral is changed in initiating the iterative process).

Subsequent lines of table Al contain the sample weight along with the corresponding humidity to which the sample was exposed until that steady-state weight had been attained.

The order of the points in table Al indicates in this illustration that a desorption process originating at a relative humidity of 1.00 was measured initially at 0.926 r.h., and finally at 0.435 . While a maximum of 33 iterations was provided for in this example, only about 20 were needed before no further change of any consequence resulted.

TABLE A1. Input data for Expt. A444153

$10063301.289000-0.000400$

1101.2942670 .926

1201.2913960 .804

$13 \quad 01.2909300 .757$

1401.2906160 .655

$15 \quad 01.2903530 .542$

1601.2901120 .435

The initiating value of $01.289000 \mathrm{~g}$ was chosen to be less than any of the data points and yet obviously greater than the expected dry weight. The choice of -0.000400 for the weight change meant that a value of $1.288600 \mathrm{~g}$ for a tentative dry weight would be tested by the computer in its next iteration. The Harkins and Jura program (HARJUR) would, of course, be used for the data file $A 444153$, since the humidities are beyond the valid range applicable to the BET theory.

In the course of the computer run the value of $\Phi$ must change signs repeatedly as it converges toward zero. This is a necessary criterion for a successful determination. The value predicted for dry weight for this particular set of data was $1.28897 \mathrm{~g}$ while the predicted ${ }^{7}$ surface area was $2.49 \mathrm{~m}^{2} / \mathrm{g}$. (Other columns present in the computer printout (not shown here) represent intermediate steps in the calculations or estimate the goodness of fit to the linear form of the isotherm equation.)

An interesting application of the computer program is the degenerate case where the iterations are suppressed. This would occur when the dry weight is

${ }^{7}$ The predicted surface area would normally not be valid in the case of a desorption experiment (such as this) unless hysteresis was absent. It is useful, however, as an estimate of the order of magnitude of the surface area. 
RQR10 PFOGEAM VASSEF (INPUT, OUTFUT, TAPEI)

Q0020*THIS PF.OGFAM IS DESICNED TO FIND THE DRY KEIGHT P(JJ) WHEFE DQӨ30*X(I) IS THE FELATIVE HUMIDITY, V(I) IS THE WEIGHT OF SAMFLE QRO4Q*AT EQUILIERUM VITH $X(I)$, AND $J$ IS THE ITEFATION OF THE PAFOQR50*AMETEF. MAX I IS II. MAX J IS JJ. THE VALUE OF II

QQQGQ*MUST EE AT LEAST 4. THE FANGE OF $X(I)$ SHOLLL EE $\oslash .08$ TO 8.33. Q0070 DIMENSION $V(50), X(50), P(99), F 3(58), F 4(58), F 5(58)$, $00080+F 6(50), F 8(50)$

QQ09Ø FEAD $(1,61)$ I I, JJ, P(1), DELP

00100 EI FORMAT ( $3 X, I 2,1 X, I 2,1 X, F 9.6,1 X, F 9.6)$

QQ118 PFINT 62

00120 E2 FOFMAT (/3X, 2HII, $1 \mathrm{X}, 2 \mathrm{HJJ}, 5 \mathrm{X}, 4 \mathrm{HP}(1), 7 \mathrm{X}, 4 \mathrm{HDELF//)}$

QQ130 PPINT $61, I I, J J, P(1)$, DELP

QR 140 P.EAL $(1,63)$ (W(I), $X(I), I=1, I I)$

QQ150 63 FOPMAT ( $3 X$, F9.6, 1X, F5.3)

QQIEO PFINT 64

Q017Q G4 FOFMAT (///5X, 4HV(I), 5X, 4HX(I)//)

Q0180 PFINT $63,(i(I), X(I), I=1, I I)$

Q0190 PFINT 65

QOEDQ 65 FOFMAT (///IX, 1HJ, 6X, 4HP(J), 8X, 3HPHI, 9X, 1HA, 9X,

$00210+1 \mathrm{HE}, 8 \mathrm{X}$, 4HAFEA, 7X, 10HMN SQF DEV//)

$8022 \varnothing$ AII $=$ II

00238 PFEPHI $=0.8$

00240 DO $104 \mathrm{~J}=1, \mathrm{JJ}$

$00250 \mathrm{GX2}=0.8$

00268 LO $92 \quad I=1$, II

$2027092 \mathrm{GX2}=\mathrm{CX}+\mathrm{X}(1) * * 2$

$0028 \theta \quad G X=0.0$

80290 DO $94 \quad I=1$, I I

$0030094 \mathrm{GX}=\mathrm{GX}+\mathrm{X}(\mathrm{I})$

$0031 \mathrm{E} L E N=A I I * G \times 2-G X * 2$

00320 DO $111 \quad I=1$, II

$00330111 F 3(I)=X(I) /(1 \cdot R-X(I)) /(V(I)-P(J))$

Q 340 GF $3=0.0$

EQ350 DO $112 \quad I=1, I I$

$00360112 \mathrm{GF} 3=\mathrm{CF} 3+\mathrm{F} 3(\mathrm{I})$

00378 LO $113 \mathrm{I}=1, \mathrm{I} I$

$e 038 R \quad 113 \quad F 4(I)=X(I) * F 3(I)$

$\varnothing 039 \ell$ GF $4=\dot{Q} . \varnothing$

00400 DO $114 \quad I=1$, II

$0 R 410114 \mathrm{GF} 4=\mathrm{GF} 4+F 4(I)$

QQ420 DO $115 \quad I=1$, II

$08430115 F 5(I)=F 3(I) * V(I) /(H(I)-P(J))$

$0044 Q$ GF $=0 . \varnothing$

00450 DO $116 \quad I=1$, I I

$00460116 \mathrm{GF} 5=\mathrm{GF5}+F 5(I)$

00470 DO $117 \quad I=1$, II

$08480117 \mathrm{~F} 6(I)=X(I) * F 5(I)$

$00490 \mathrm{GF} 6=\varnothing .0$

00500 DO $118 \quad I=1$, I I

$00510118 \mathrm{GFE}=\mathrm{GFE}+\mathrm{FE}(\mathrm{I})$

00520 DO $119 \quad I=1$, I I

$Q 8530119 F 8(I)=F 3(I) * F 5(I)$

00540 GF $8=0.0$

00550 DO $120 \quad I=1$, I I

$80560120 \mathrm{GF}=\mathrm{GF}=\mathrm{FB}(\mathrm{I})$

$08570 A=18 . \theta * P(J) *(G X 2 * G F 3-G X * G F 4) / D E N$

$00580 E=18.8 * P(J) *(A I I * G F 4-C X * G F 3) / D E N$

$00590 \mathrm{APEA}=7.529 E+C 4 /(A+E)$

$006 \ell 0 \mathrm{PHI}=A * G F 5+B * G F 6-18.0 * P(\mathrm{~J}) * G F 8$

$D Q E I C$ SSQP.S $=0.0$

08620 DO 4 I $=1$, II

006304 SSQRS $=$ SSQRS + (V(I) $-P(J) *(1.0+18.0 * X(I))$

$\theta 064 \theta+(1.0-X(I)) /(A+E * X(I)))) * * 2$

QQ650* SSQRS OF DEVS OF V(I) FFOM CURVELINEAF. FEGFESSION

$\theta \varnothing 66 \emptyset$ VAF $=$ SSGP.S/(AII - 3. $\theta)$

QQEG7R PFINT 99, J, $P(J)$, PHI, A, E, AFEA, VAF

QE680 99 FOFMAT (I2, 2E13.5, 2E1E.2, 2E12.4)

00690 IF (PHI*PFEPHI) $95,96,96$

0070095 DELP $=-\ell .1 *$ LELP

0071096 PREPHI = PHI

$00720 P(J+1)=P(J)+$ LELP

00730104 CONTINUE

00740 STOP

00750 ENI

Figure Al. Computer Program, WASSER, (FORTRAN IV) for determination of unbound water content (dry weight) and Surface Area from water vapor sorption data according to the BET adsorption theory. 
$\oslash \oslash \oslash 1 \oslash$ PFOGFAM HAFJUF.(INFUT, OUTPUT, TAFE1)

Ө0020*THIS PFOCFAM IS DESIGNED TO FIND THE DFY KEIGHT P(JJ)

QQR 3ø* HHEFE $X(I)$ IS THE FELATIVE HUMIDITY, V(I) IS THE

QØQ40*EIGHT OF SAMPLE AT EGUILIEFLM WITH X(I), ANL $J$ IS THE

ØOØ5Q*ITERATION OF THE PAFAMETEF, MAX I IS II. MAX J IS JJ.

RQӨGQ*THE VALLE OF II MUST EE AT LEAST 4.

QRO7Ø DIMENSION $V(5 \ell), X(5 \ell), P(99), H I(50), H 2(58)$

00080 READ $(1,61)$ II, JJ, $P(1)$, DELP

๑0090 61 FOFMAT ( $3 \mathrm{X}, \mathrm{I} 2,1 \mathrm{X}, \mathrm{I} 2,1 \mathrm{X}, \mathrm{F9.6}, 1 \mathrm{X}, \mathrm{F9.6})$

DQIQO PFINT 62

QE110 62 FOPMAT (/3X, 2HII, 1X, 2HJJ, 5X, 4HP(1), 7X, 4HEELP//)

RØ120 PEINT 61, II,JJ, P(1), DELP

RD 130 READ $(1,63) \quad(W(I), X(I), I=1, I I)$

QR 140 \& 3 FOFMAT $(3 X, F 9.6,1 X, F 5.3)$

ROI50 PFINT $\in 4$

0016864 FOFMAT (///5X, 4HV(I), 5X, 4HX(I)//)

EQ 170 PR.INT $63,(W(I), X(I), I=1, I$ I )

$\emptyset 0180$ PFINT 65

0019065 FOFMAT (////1X, 1HJ, $6 X, 4 \mathrm{HP}(J), 8 \mathrm{X}, 3 \mathrm{HPHI}, 9 \mathrm{X}$,

$0820 \ell+1 \mathrm{HA}, 9 \mathrm{X}, 1 \mathrm{HE}, 8 \mathrm{X}, 4 \mathrm{HAFEA}, 7 \mathrm{X}, 10 \mathrm{HMN}$ SGF DEV///)

$00210 \mathrm{AII}=\mathrm{II}$

00220 PFEPHI $=0 . \varnothing$

00230 DO $104 \mathrm{~J}=1, \mathrm{JJ}$

$0024 \ell$ DO $90 I=1$, I I

$\theta 025090 \mathrm{HI}(\mathrm{I})=\operatorname{ALOG}(1 . \theta / \mathrm{X}(\mathrm{I}))$

$00260 \mathrm{GH} 1=\mathrm{H} 1(1)$

80270 DO 91 I $=2$, II

OR280 $91 \mathrm{CHI}=\mathrm{GHI}+\mathrm{H} 1(\mathrm{I})$

Øह290 DO $92 \mathrm{I}=1, \mathrm{II}$

QQ3e0 $92 \mathrm{H} 2(\mathrm{I})=1.0 /(\mathrm{H}(\mathrm{I})-\mathrm{P}(\mathrm{J}))$

$00310 \mathrm{GH} 2=\mathrm{H} 2(1) * * 2$

00320 DO $93 \mathrm{I}=2$, II

$8033893 \mathrm{GH} 2=\mathrm{GH} 2+\mathrm{H} 2(\mathrm{I}) * * 2$

eथ $340 \mathrm{GH} 12=H 1(1) * \mathrm{H} 2(1) * * 2$

RR350 IO $94 I=2, I I$

$0036094 \mathrm{GH} 12=\mathrm{GH} 1 \mathrm{C}+\mathrm{H} 1(\mathrm{I}) * \mathrm{H} 2(\mathrm{I}) * * 2$

$00370 \mathrm{GH} 4=\mathrm{H} 2(1) * * 4$

QR $38 R$ DO $95 I=2$, I I

$0839 \ell 95 \mathrm{CH} 4=6 H 4+H 2(I) * * 4$

00400 GHV $3=W(1) * H 2(1) * * 3$

00410 DO $96 I=2$, I I

$0842096 \mathrm{GHV}=\mathrm{GHW} 3+\mathrm{V}(\mathrm{I}) * \mathrm{H} 2(\mathrm{I}) * * 3$

$00430 \mathrm{GH} 1 \mathrm{H}=\mathrm{l}(1) * \mathrm{H} 1(1) * \mathrm{H} 2(1) * * 3$

00440 DO $97 \mathrm{I}=2$, II

$8845097 \mathrm{GH} 1 \mathrm{~V}=\mathrm{GH} 1 \mathrm{H} 3+\mathrm{V}(\mathrm{I}) * \mathrm{H} 1(\mathrm{I}) * \mathrm{H} 2(\mathrm{I}) * * 3$

00460 GHW $5=W(1) * \mathrm{H} 2(1) * * 5$

00470 DO $98 \mathrm{I}=2$, II

$8048098 \mathrm{GH} 5=\mathrm{CHW} 5+\mathrm{H}(\mathrm{I}) * \mathrm{H} 2(\mathrm{I}) * 5$

$00490[E N=(18 . \ell * \mathrm{P}(J)) * 2 *(\mathrm{AII} * \mathrm{GH} 4-\mathrm{GH} 2 * 2)$

$0 R 5 R \emptyset$ ANUM $=A I I * G H 12-\mathrm{GH} 1 * \mathrm{GH} 2$

CO510A $=$ ANUM $/ D E N$

00520 ENIM $=(18 . \theta * \mathrm{P}(\mathrm{J})) * * 2 *(\mathrm{GH} 2 * \mathrm{GH} 12-\mathrm{GH} 1 * \mathrm{GH} 4)$

$00530 \mathrm{~B}=\mathrm{ENUM} / \mathrm{DEN}$

$\oslash \oslash 540 \mathrm{PHI}=A * P(J) *(G H 1 V 3-A *(18 \cdot \theta * P(J)) * * 2 * G H W 5+E * G H W 3)$

00550 SSQF.S $=0.0$

00560 DO 4 I $=1$, I I

$00570 \mathrm{DISC}=\mathrm{A} /(\mathrm{HI}(\mathrm{I})+\mathrm{E})$

00580 IF (DISC) $70,69,69$

0059069 DSCR = DISC

$\emptyset \emptyset 6 \boxminus 0 \mathrm{SSQFS}=\mathrm{SSQRS}+(W(I)-P(J) *(1 . \theta+18 \cdot \theta * S Q F . T(L S C F))) * * 2$

00610 GO TO 4

$\oslash 062070$ SSQF.S $=1.0 E+\oslash 8$

ØR630 4 CONTINUE

Q0640* SSQFS OF DEVS OF $V(I)$ FFOMM CURUILINEAF. REGRESSION

RØ650 VAF $=S S Q F S /(A I I-3.0)$

$\theta \theta 66 \theta$ IF (A.LT. $\theta . \theta)$ GO TO 111

$\theta 0670$ AFEA $=5.62 E+\emptyset 4 * \operatorname{SQRT}(A)$

DE 680 GO TO 112

00690111 AFEA $=0.0$

00700112 PFINT 99, J, P(J), PHI, A, E, AFEA, VAF.

0071099 FOPMAT (I2, 2E13.5, 2E10.2, 2E12.4)

00720 IF (J.EQ.1) $C O$ TO 101

00730 IF (PHI*PREPHI) $100,100,101$

00740100 DELP $=-0.1 *$ DELP

00750101 PPEPHI $=$ PHI

$00760 P(J+1)=P(J)+D E L P$

00770104 CONTINUE

Ө078R STOP

00790 END

Figure A2. Computer Program, HARJUR, (FORTRAN IV) for determination of unbound water content (dry weight) and Surface Area from water vapor sorption data according to the H-J adsorption theory. 
available experimentally along with the rest of the data points and the experimenter is primarily interested in the least-squares value of the surface area. In the first line of the input data file (table Al) he would set the number of iterations equal to 01 and would insert the known dry weight for the initial value of $p$ which is the next entry on that same first line. The final entry (corresponding to the initial decrement) while it will be ignored by the computer should, never-the-less, be present even if all its digits are zeroes.

The computer programs used in this work are reproduced in figures $\mathrm{Al}$ and $\mathrm{A} 2$.

\section{References}

[1] Brunauer, S., Emmett, P. H., and Teller, E., Adsorption of gases in multimolecular layers, J. Am. Chem. Soc. 60, 309-319 (1938).

[2] Dubinin, M. M., Zaverina, E. D., and Radushkevich, L. V., Sorption and structure of activated carbon, I. Investigation of adsorption of organic vapors, Zhur Fizich Khim 21, 1351-1362 (1947).

[3] Harkins, W. D., and Jura, G., Surfaces of solids XIII. A vapor adsorption method for the determination of the area of a solid without the assumption of a molecular area, and the areas occupied by nitrogen and other molecules on the surface of a solid, J. Am. Chem. Soc. 66, 1366-1373 (1944).
[4] Halsey, G. D., Jr., A new multilayer isotherm equation with reference to surface area, J. Am. Chem. Soc. 73, 2693-2696 (1951).

[5] Pierce, C., The Frenkel-Halsey-Hill Adsorption Isotherm and Capillary Condensation, Proc. of the 34th National Colioid Symposium (American Chemical Society), Lehigh Univ., Bethlehem, Pa. 64, 86-89 (1960).

[6] Adamson, A. W., Physical Chemistry of Surfaces, (Interscience Publishers, Inc., New York, N.Y., 1960), p. 501.

[7] Venkateswaran, A., Sorption of aqueous and non-aqueous media by wood and cellulose, Chem. Reviews 70, 619-637 (1970).

[8] Scarborough, J. B., Numerical Mathematical Analysis, 2d Ed. (The Johns Hopkins Press, Baltimore, 1950), pp. 451-469.

[9] Adamson, A. W., Physical Chemistry of Surfaces, (Interscience Publishers, Inc., New York, 1960), pp. 499-500.

[10] Loebenstein, W. V., Adsorption of water on tooth components and related materials, J. Dent. Res. 52, 271-280 (1973).

[11] Rao, K. S., Hysteresis in sorption, II, III, IV, V, J. Phys. Chem. 45, 506-531 (1941).

[12] Loebenstein, W. V., The surface area of aggregates applied to dental materials, J. Biomedical Materials Res. 9, 35-53 (1975).

[13] Everett, D. H., Adsorption Hysteresis, The Solid Gas Interface, Chapter 36, Flood, E. A. Ed. (Marcel Dekker, Inc., N.Y., 1967).

[14] Tietjen, G. L., Moore, R. H., and Beckman, R. J., Testing for a Single Outlier in Simple Linear Regression, Technometrics 15, 717-721 (1973).

(Paper 79A4-860) 